\title{
LA MEDIACIÓN PENAL: ¿QUIMERA O REALIDAD?*
}

\author{
Marien Aguilera Morales \\ PROFESORA TITUlar DE DERECHO PROCESAL \\ UNIVERSIDAD COMPLUTENSE DE MADRID
}

SUMARIO: I. La mediación penal: un instrumento para la puesta en práctica de un nuevo modo de concebir la Justicia penal. II. Elementos esenciales. III. La mediación en el sistema de Justicia penal español: entre la Ley y la práctica. III.r. La mediación juvenil o de menores. III.2. La mediación de adultos. IV. Ante el reto de dar cobertura legal a la mediación penal en el enjuiciamiento penal de adultos. IV.r. La mediación en clave de principios. IV.2. La mediación en clave de derechos y garantías. IV.3. Algunas propuestas con vistas a la implantación legal de la mediación en nuestro sistema.

RESUMEN: En el presente trabajo nos acercamos a la Justicia restaurativa como nueva forma de concebir la Justicia penal y a los elementos esenciales de la mediación penal. El estudio e extiende sobre los escollos y riesgos que habrán de sortearse en un futuro cuando nuestro legislador proceda a dar cobertura legal a este instrumento en el enjuiciamiento penal de adultos.

PAlABRAS ClAVE: justicia restaurativa, conflicto penal, víctima, reforma legal, principios del proceso penal, mediación penal, mediación juvenil.

\section{CRIMINAL MEDIATION: CHIMERA OR REALITY?}

ABSTRACT : This work focuses on restaurative law as a new way of thinking of criminal justice, and the essential elements of criminal mediation. The study focuses on the points that the legislator will have to solve in order to create a new criminal law.

KEYWORDS: restaurative justice, criminal conflict, victim, legal reform, criminal proceeding principles, criminal mediation, juvenile mediation.

\footnotetext{
* El presente estudio parte de la ponencia que, con el mismo título, fue presentada al Congreso sobre Mediación y Arbitraje Nacional e Internacional: Perspectivas de futuro, celebrado en Logroño los días I4 y I5 de marzo de 20II, y se ha realizado al amparo del Proyecto Nacional I+D «Instrumentos de Justicia Restaurativa en el proceso penal español: hacia una regulación de la mediación penal» (Ref. DER 2008-03547/JURI), cuyo Investigador principal es Pedro M. Garciandía González.
} 


\section{La mediación penal: un instrumento para la puesta en práctica de un nuevo modo de concebir la justicia penal}

『. Pasan ya más de seis años desde que me acerqué por primera vez al estudio de la mediación penali. En aquel entonces me declaré escéptica respecto de las pretendidas bondades que podría suponer su implantación en nuestro sistema penal y, más concretamente, en nuestro proceso penal de adultos. Mentiría si afirmara que esa opinión ha cambiado radicalmente con los años. Hoy, en efecto, sigo teniendo la convicción de que la mediación penal dista de ser la panacea a los males que aquejan nuestra Administración de Justicia penal y también sigo albergando ciertos reparos hacia la institución, atendidos los escollos de todo tipo que deben sortearse para su implantación en nuestro Ordenamiento jurídico.

He de reconocer, sin embargo, que mi actual escepticismo acerca de la posibilidad de que la denominada «cultura de la mediación» trascienda a nuestro sistema penal y procesal penal es menos acusado que en el pasado. Hoy, ciertamente, creo muy probable que se dé cobertura legal a la mediación en el ámbito del proceso penal de adultos. Y lo creo no sólo porque constituya un imperativo comunitario, por la influencia que en este sentido puede operar el Derecho comparado o por la conveniencia, en fin, de respaldar legalmente lo que de facto hace tiempo que constituye una realidad en muchos de Juzgados y Tribunales penales. Mi creencia radica, fundamentalmente, en que tras todas estas circunstancias existe una nueva forma de concebir la Justicia penal que parece estar imponiéndose a la concepción netamente retributiva del Derecho penal y del proceso penal como instrumento para su aplicación.

『. La filosofía a que me refiero es la propia de la «Justicia restaurativa» (o, con otra nomenclatura, de la Justicia «restauradora» o «reparadora»): una forma de concebir la Justicia penal que toma como base un presupuesto antropológico -una visión amable del ser humano- y por finalidad humanizar el sistema penal y procesal penal, restaurando a la víctima, al propio delincuente y la sociedad entera a la situación anterior a la comisión del hecho delictivo.

En el origen -que bien pueden situarse a mediados del siglo pasado- de este modo de concebir la Justicia penal, confluyeron dos circunstancias: de un lado, la proliferación de ciertos movimientos sociales a favor de los derechos humanos y de la resolución de los conflictos centrada en el diálogo; de otro lado, el nacimiento de corrientes muy críticas con el tradicional modelo de Justicia penal, atendida su destacada finalidad retributiva y la absoluta falta de atención que desde él se dispensa a las víctimas del delito².

La conjunción de ambas circunstancias llevó, ciertamente, a acuñar la idea de que al Derecho Penal también le incumbe estañar las heridas causadas por el delito y resolver el conflicto desencadenado por éste. El delito visto desde esta perspectiva comporta, así, y en primerísimo término, un conflicto entre personas, que no puede resolverse -o mejor, que no sólo puede resolverse- inflingiendo un castigo al delincuente, sino procurando su rehabilitación por la vía de que tome conciencia del mal realizado a la víctima y a la propia comunidad y de que proceda a su subsanación mediante la restauración del daño causado. Es en este sentido y no en otro que a la Justicia restaurativa puede considerársele como una «alternativa» al sistema de Justicia vindicativa. Con otras palabras: si cabe presentar a la Justicia restaurativa en términos de alternativa a nuestro actual sistema de Justicia penal no es tanto porque se piense en aquélla en términos de disyuntiva o exclusión respecto de ésta,

\footnotetext{
${ }^{I}$ Vid. «La mediación como 'alternativa' al proceso penal de adultos: ¿de la práctica a la Ley?» en Problemas actuales del proceso iberoamericano, XX Jornadas iberoamericanas de Derecho Procesal, Tomo I, pp. 279 a 293.

2 Para un estudio en profundidad de los orígenes y desarrollo de la Justicia restaurativa, v.: http://www.restorativejustice.org/.
} 
cuanto porque los postulados propios de la Justicia restaurativa atienden principalmente a restituir a la víctima y a lograr la rehabilitación del autor de la infracción.

Como apuntábamos, este pensamiento -que, en expresión prestada, va más allá del «buen rollito» o del deseo de insuflar una «dosis de bondad» en el arsenal punitivo del Estado $^{3}$ - y la terminología en que se expresa ${ }^{4}$, se han expandido muy rápidamente y con alcance mundial ${ }^{5}$. En este hito, la Justicia restaurativa ha contado con un magnífico campo de cultivo: la tendencia -también mundial- de promocionar «técnicas o prácticas alternativas de resolución de conflictos».

No es de extrañar, por lo expuesto, que la filosofía de la Justicia restaurativa sirva de «paraguas» a una amplia y variada gama de técnicas, entre las que destacan los programas de reconciliación víctima-agresor (los VORP o VOP), los conocidos como «conferencias de familia» $\mathrm{y}$ «círculos de sentencia» ${ }^{6}$, y la propia mediación penal.

Y no es de extrañar, por lo mismo, que la idea de introducir la mediación en el sistema penal actual cuente con el aval de Naciones Unidas, del Consejo de Europa y de la propia Unión Europea, tal y como revelan las numerosas propuestas, recomendaciones e instrumentos normativos pergeñados desde estas instancias?

\footnotetext{
${ }^{3}$ El «prestamista» es Del Moral García, A. «La mediación en el proceso penal. Fundamentos, problemas, experiencias», en La mediación. Presente, pasado y futuro de una institución jurídica (Dir. RodrígUEZ-ARANA Y DE PRADA), Ed. Netbiblo, Madrid, 2010, p. 52.

${ }^{4}$ Nótese que esta nueva forma de concebir la Justicia penal comporta una terminología también en todo ajena a la propia de la Justicia penal clásica. No se habla de delitos, delincuentes u ofendidos, sino de infractores y víctimas, y de conflictos entre aquéllos y éstas.

${ }^{5}$ Ilustrativo en este sentido es el trabajo de PeCEs MoRATE, J. E., «La mediación en la Jurisdicción Penal», en Derecho Penal y Justicia en el siglo XXI, Liber amicorum elaborado como homenaje a Antonio González Cuellar, Ed. Comares, Granada, I998. Asimismo puede consultarse el más reciente y exhaustivo trabajo de BARONA VILAR, S., La mediación penal para adultos. Una realidad en los ordenamientos jurídicos, ed. Tirant lo Blanch, Valencia, 2009 .

${ }^{6}$ Los VORP (Victim Offender Reconciliation Program) fueron impulsados por miembros de la comunidad menonita en Canadá a mediados de los años 70. En la década siguiente, y en Estados Unidos, surgieron los VOP (Victim Offender Program), basados como aquéllos en reparar los efectos que en víctima e infractor produce la comisión del delito, sobre la premisa de que a éste subyace, en verdad, un conflicto bilateral.
}

A diferencia de los anteriores, las «conferencias de familia o grupos de comunidad» y los «círculos de sentencia» son técnicas que involucran a otros sujetos en la solución del conflicto. Nacidos los primeros en Nueva Zelanda y heredados los segundos de ciertas prácticas nativas americanas, son comúnmente utilizados en Norte América, Australia y Sudáfrica.

7 En el ámbito de Naciones Unidas, cabe destacar la Resolución I999/26, de 28 de julio de I999, del Consejo Económico y Social, sobre el desarrollo y la aplicación de medidas de mediación y de Justicia reparadora en el Derecho Penal; así como la Resolución 2000/I4, de 7 de julio de 2000, también del Consejo Económico y Social, sobre principios básicos del uso de programas de justicia reparadora en asuntos criminales. En el del Consejo de Europa, proliferan por su parte las Recomendaciones del Comité de Ministros para la implantación de la Justicia restaurativa a través de la mediación penal. Así: Recomendación $n^{\circ} \mathrm{R}(83) 7$, sobre mediación como fórmula de sustitución de la pena privativa de libertad; Recomendación $n^{\circ} \mathrm{R}(85)$ II, sobre la posición de la víctima en el marco del Derecho Penal y del procedimiento penal; Recomendación $\mathrm{n}^{\circ} \mathrm{R}(87)$, sobre simplificación de la Justicia Penal: mediación y reparación como estrategias de evitación del proceso penal; Recomendación $n^{\circ} R(87) 20$, sobre reacciones sociales frente a la delincuencia juvenil: la mediación como medio de evitación de la pena privativa de libertad en Derecho Penal Juvenil; y Recomendación $n^{\circ} \mathrm{R}$ (99) I9, relativa a la mediación en materia penal. Finalmente, en la Unión Europea, además de la DM 200I/220/JAI a que se alude en texto, debe llamarse la atención acerca de la Iniciativa que, en junio de 2002, presentó el Gobierno belga al Parlamento Europeo relativa a la creación de una red europea de puntos de contactos nacionales para la justicia reparadora. El texto de esta Iniciativa y de la Resolución del Parlamento europeo pueden consultarse en: <http://www.europarl.europa.eu/sides/getDoc.do?pubRef=//EP//TEXT+TA+20030408 +ITEMS+DOC+XML+Vo//ES\&amp;language=ES\#sdoctaI7>. Sobre éstas y otras iniciativas internacionales en materia de Justicia restaurativa y mediación penal, vid. Revilla GonZÁLEZ, J. A. «La mediación penal», en Mediación y solución de conflictos (Coord. SolETo MuÑoz y OTERo PARGA), Ed. Tecnos, Madrid, 2007, esp. pp. 307 a 3IO. 
En este último orden de cosas, no puede dejar de destacarse lo dispuesto en la Decisión Marco del Consejo de la Unión Europa de I5 de marzo de 200I (200I/220/JAI), relativa al Estatuto de la Víctima en el proceso penal, cuyo artículo io anima a los Estados a impulsar la mediación para las infracciones que a su juicio se presten a este tipo de medida, así como a tomar en consideración todo acuerdo entre víctima e inculpado alcanzado con ocasión de la mediación en las causas penales ${ }^{8}$.

El carácter obligado de la cita descansa en que este instrumento normativo constituye, según también apuntábamos, un imperativo para que los Estados miembros incorporen la mediación a sus respectivos sistemas penales y procesales penales ${ }^{9}$, lo que, por cierto, ya han hecho algunos Estados de nuestro entorno más próximo como Francia, Bélgica o Portugal. De España, sin embargo, ni puede decirse que haya cumplido en tiempo las exigencias europeas ${ }^{\mathrm{I}}$, ni defender con seriedad que ha respondido a las mismas por la vía de regular legalmente la mediación en el enjuiciamiento penal de menores. La Decisión Marco 200I/220/JAI -nos parece- exige incorporar la mediación penal al enjuiciamiento penal de adultos; y esto es algo que, en nuestro sistema, resulta, hoy por hoy, claramente alegal.

『. La probabilidad de que en un futuro nuestro legislador ponga fin a esta situación de anomia nos anima a escribir estas páginas, dirigidas fundamentalmente a poner de relieve los escollos y riesgos que -pensamos- habrán de sortearse al efecto.

Antes, sin embargo, consideramos imprescindible dar siquiera somera cuenta de los elementos esenciales de la mediación penal y del modo en que este instrumento de la Justicia restaurativa ha calado en nuestro sistema. En este propósito, nos moveremos en dos planos -el de la legalidad y el de la práctica vigente-, que respectivamente se corresponden con el enjuiciamiento de menores de edad penal y con el enjuiciamiento de adultos ${ }^{\mathrm{II}}$.

\section{Elementos esenciales}

『. En palabras del Comité de Ministros del Consejo de Europa, la mediación penal es un procedimiento a través del cual «víctima e infractor, voluntariamente, se reconocen capacidad para participar activamente en la resolución de un conflicto penal, gracias a la ayuda de un tercero imparcial: el mediador ${ }^{\mathrm{I2}}{ }$.

Así definida, es claro que, en el ámbito penal, la finalidad de la mediación es contribuir a que víctima e infractor resuelvan «su» conflicto; objetivo que -añadimos- sólo se conseguirá por la vía de la conciliación y/o de la reparación ${ }^{\mathrm{I3}}$. El añadido es importante,

\footnotetext{
${ }^{8}$ La propia Decisión Marco define en su artículo I e) la mediación penal como «la búsqueda, antes o durante el proceso penal, de una solución negociada entre la víctima y el autor de la infracción, en la que medie una persona competente».

9 Un análisis comparativo de la implantación de la Justicia restaurativa en Europa puede encontrarse en «Restorative Justice Development in Europe», desarrollado dentro del programa COST Action A 2I. En lengua española, puede consultarse asimismo el trabajo de RoMera AnTón, C., «Conferencias comunitarias y justicia restaurativa», en Estudios de Derecho Judicial, CGPJ, 2007, núm. I36, pp. I89 a 206.

Io El plazo previsto en el artículo I7 de la Decisión Marco para dar cumplimiento a sus disposiciones, concluyó en marzo de 2006.

${ }^{\text {II }}$ Respecto de ambos extremos buena parte de lo que se expone fue ya apuntado en el citado trabajo «La mediación como 'alternativa' al proceso penal de adultos: ¿de la práctica a la Ley?», cuyo contenido rescatamos en lo esencial para actualizarlo y amoldarlo al principal objetivo de estas páginas.

I2 Tomamos la definición de la ya citada Recomendación nº R (99) I9, sobre mediación penal.

${ }^{13}$ Cfr. Del Moral García, A. «La mediación en el proceso penal. Fundamentos, problemas, experiencias», cit. p.5I
} 
porque, tal y como venimos defendiendo, la mediación penal no es más que un instrumento al servicio de una concepción de la Justicia penal caracterizada por buscar la pacificación del conflicto que subyace a la comisión del delito (lo que es propio de la conciliación) y reparar a la víctima de los daños ocasionados (lo que es propio de la reparación). De aquí, que a la mediación penal se le conozca también bajo la expresión de «mediación penal reparadora». Que entre mediación penal, de un lado, y conciliación y reparación, de otro, haya una relación medio-fin no debe, por lo demás, llevar al error de equiparar conceptos, pues cabe que la mediación no logre ni la conciliación ni la reparación; que la conciliación o la reparación se produzca sin previa mediación; o que se dé conciliación sin reparación, y al revés: reparación sin conciliación.

De aquella definición también se infieren los elementos esenciales -«o principios generales», como conviene en denominar a alguno de ellos el propio Comité de Ministros del Consejo de Europa- de la mediación penal. En esencia, son los siguientes:

a) Voluntariedad. El inicio y desarrollo de la mediación penal requieren inexcusablemente que víctima y agresor consientan participar en ella. Este consentimiento debe emitirse de modo libre y consciente, lo que excluye, de un lado, cualquier medio dirigido a doblegar o dirigir la voluntad de las partes con vistas a que éstas accedan a someterse al procedimiento mediador, y exige, de otro, informarles de cómo se desarrollará la mediación penal, de las ventajas e inconvenientes que, para cada una, puede reportar someterse a ella y, sobre todo, de las consecuencias que pueden seguirse tanto se logre un acuerdo como no.

La voluntariedad que informa la mediación penal implica, además, que las partes puedan retractarse en cualquier momento de participar en ella, sin que de tal retractación puedan seguirse consecuencias negativas de índole procesal o penal.

b) Confidencialidad. Elemento también esencial y peculiar de la mediación penal es que el contenido de las entrevistas y conversaciones realizadas con ocasión de ellas son estrictamente confidenciales. Coherentemente con ello, al mediador le incumbe el deber de secreto profesional.

Ni que decir tiene que este elemento constituye un acicate para que las partes decidan someterse a la mediación penal, pues la privacidad en que ésta se desarrolla y el hecho de que las declaraciones vertidas durante el procedimiento mediador carezcan de trascendencia jurídica, fomentan la confianza -sobre todo la del infractor- de someterse a ella.

c) Imparcialidad. A la naturaleza autocompositiva de la mediación no obsta en modo alguno el protagonismo que en ella ostenta el mediador, cuyos conocimientos y habilidades profesionales deben ponerse al servicio de las partes, ofreciéndoles soluciones satisfactorias pero sin actuar a favor de ninguna de ellas ni imponerles un concreto acuerdo. La labor del mediador consiste, pues, en ayudar, desde una posición de estricta imparcialidad, a que víctima e infractor alcancen un acuerdo con el que poner solución al conflicto generado entre ellas.

d) Accesibilidad y autonomía respecto del sistema de justicia penal. Al menos en su modalidad intraprocesal, la mediación debe ser un servicio accesible en cualquier fase del proceso y estar a disposición de cualquier persona implicada en una infracción penal. Con todo, debe guardar un cierto grado de autonomía dentro del sistema de Justicia tradicional, lo que hace pensar en ella como un servicio institucional de la Administración de Justicia pero independiente del Poder Judicial ${ }^{14}$.

I4 En el mismo sentido MARTín Diz, F., La mediación: sistema complementario de Administración de Justicia, Consejo General del Poder Judicial, Madrid, 20I0, p. 331. 
A los mencionados deben unirse también otros criterios que convienen en considerarse esenciales a la mediación penal como la gratuidad del servicio y la flexibilidad o informalidad que debe presidir aquélla, al objeto de que el eventual acuerdo entre las partes no sólo se logre, sino que también se alcance con rapidez.

『. La sencillez que comporta precisar los criterios o principios esenciales de la mediación penal se torna, empero, dificultad a la hora de delinear su ámbito de aplicación, su procedimiento y su eficacia, atendidas las muy diversas modalidades que aquélla adopta en los países en que se ha implantado y, aun dentro de un mismo país, de los concretos supuestos en que la mediación se aplica.

En un esfuerzo de elevar a género las categorías, puede afirmarse que, en lo que hace a su ámbito objetivo de aplicación, la mediación adopta dos modalidades básicas: una, primera, ceñida a cierto tipo de infracciones penales (faltas o delitos menos graves, delitos privados o semipúblicos, etc.); y una segunda modalidad conforme a la que, en principio, ningún tipo de infracción penal estaría apriorísticamente excluido de la mediación, si bien algunas de esas infracciones pueden resultar excluidas posteriormente por la aplicación de determinados parámetros de selección (características del hecho delictivo, circunstancias de su comisión, personalidad y antecedentes de su autor, entidad del daño causado, unidad o pluralidad de víctimas y de infractores, etc.).

También desde un punto de vista subjetivo son varias las modalidades de mediación que cabe destacar. Así, tomando como referente al sujeto activo de la infracción penal -al infractor o victimario-, la mediación puede operar respecto de menores de edad penal (mediación de menores o juvenil) y/o respecto de mayores de edad penal (mediación de adultos). Por el contrario, tomando como referente al sujeto pasivo de la infracción penal -a la víctima-, cabe distinguir entre aquellos casos en que la mediación toma como premisa un concepto estricto de víctima y, por tanto, sólo resulta accesible en aquellos supuestos en que la infracción produce un daño o perjuicio real a una o varias personas, sean éstas físicas o jurídicas; y aquellos otros casos, en cambio, en que la mediación toma como premisa un concepto amplio de víctima, en que se incluye no sólo al ofendido o perjudicado por el hecho delictivo, sino también a la propia sociedad o comunidad. Ni que decir tiene que este concepto amplio de víctima extiende extraordinariamente el ámbito de aplicación de la mediación penal, hasta el punto mismo de hacerla posible respecto de determinados tipos delictivos que en otro caso no serían «mediables», como los denominados delitos de riesgo o de mera actividad.

En lo que hace al procedimiento mediador, éste suele estructurarse en tres fases:

La primera de esas fases se corresponde, obviamente, con su inicio, siendo habitual en este sentido que la mediación penal responda a la «oficialidad» o, lo que viene a ser lo mismo, a la decisión de «derivación» por parte de las denominadas autoridades de la persecución penal -Policía, Fiscal o Juez- o incluso del propio servicio de mediación. Esto no obstante, la decisión de que el asunto «derive» a la mediación penal puede obedecer también a la solicitud que en este sentido formule el infractor e incluso la víctima, si bien, de entre todos, éste suele ser el supuesto más anómalo.

Derivado, de cualquier forma, el asunto al servicio de mediación, comienza una segunda fase, de contenido esencialmente informativo pero determinante del éxito mismo del procedimiento. En esta fase, el mediador debe ponerse en contacto con las partes, al objeto de informarles, sí, de las ventajas que para cada una de ellas puede seguirse de la mediación y del eventual acuerdo al que se llegue, pero también de indagar sobre su predisposición a encontrar una solución al conflicto en que se han visto implicadas. Sólo si esa predisposición es común a víctima e infractor se pasa a la siguiente fase. 
La tercera y nuclear fase de la mediación es la fase de contactos entre víctima e infractor, en el bien entendido que, en principio, los contactos se realizan entre víctima y mediador, de un lado, e infractor y mediador, de otro lado (mediación indirecta), pudiendo posteriormente extenderse a víctima e infractor conjuntamente (mediación directa). Si esta fase de contactos no fructifica en la reparación a la víctima o en la conciliación entre ésta y el infractor, la mediación habrá fracasado: no evitará la imposición de la pena o medida prevista por ley, ni que ésta se imponga a través de un proceso. Por el contrario, si víctima e infractor llegan a un acuerdo o, más precisamente, existe un compromiso por parte de este último de reparar el daño ocasionado por el delito, el mediador redactará un informe o acta en que se hará constar el acuerdo o compromiso alcanzado y que, en su caso, remitirá al órgano encargado de la dirección del proceso en ese momento, al objeto de que se anude la eficacia jurídica que corresponda.

En relación con esto último, conviene hacer dos precisiones, relativa la primera al acuerdo en sí y a su posible contenido, y la segunda a la eficacia jurídica que este acuerdo y el cumplimiento de los compromisos adquiridos pueden desplegar.

En lo que hace a lo primero -i.e. al contenido del acuerdo alcanzado entre infractor y víctima-, importa destacar que tal contenido puede ser muy diversa índole. Así, puede consistir en la reparación económica de los daños patrimoniales ocasionados por el delito y concretarse, por ejemplo, en la restitución de la cosa o en el desembolso de una cantidad de dinero. Puede consistir, igualmente, en la reparación de los daños morales ocasionados a la víctima, caso en que el acuerdo suele comportar la petición de perdón por parte del infractor e incluir la asunción (por éste pero también por la víctima) de ciertas pautas de conducta dirigidas a solventar la situación conflictiva que subyace a la comisión del hecho delictivo. Y también existe la posibilidad de que el acuerdo se concrete en la realización de una actividad dirigida, no tanto a reparar económica o moralmente a la víctima, cuanto a reparar los daños que el delito ha ocasionado a la sociedad en sí y a favorecer la rehabilitación del infractor (tal sería el caso, por ejemplo, de que éste se comprometiera a asistir a cursos de educación vial, o consintiera su ingreso en un centro psiquiátrico o el sometimiento a un tratamiento deshabituador). Estos posibles contenidos -susceptibles todos ellos de combinarse entre sí e incluso de integrar un mismo acuerdo- revelan bien a las claras que el acuerdo reparador no es un acuerdo en torno a la denominada acción civil ex art. Ioo LECrim. Y no lo es, no sólo -que también- porque la reparación puede ser de tipo simbólico, sino porque ésta puede producirse allí incluso donde del hecho ilícito no se derive responsabilidad civil.

En cuanto a lo segundo -i.e., a los efectos jurídicos del acuerdo reparador y del cumplimiento de los compromisos alcanzados-, es de hacer notar que tales efectos pueden ceñirse a la pena o a la medida de seguridad que legalmente correspondiera imponer al infractor o, por el contrario, extenderse al proceso. Más claramente: en ocasiones, el logro de un acuerdo tras la mediación juega sólo como «alternativa a la pena»; aquél, por tanto, ninguna trascendencia tiene sobre el proceso, que se tramita por su cauce habitual hasta el momento de dictar sentencia, en la que -eso sí- ha de atenderse al acuerdo alcanzado con vistas bien a mitigar la pena o medida de seguridad que deba imponerse, bien a suspender su aplicación, bien incluso a excluir aquélla. En otras ocasiones, sin embargo, el acuerdo alcanzado juega como «alternativa al proceso» en la medida en que despliega su eficacia bien excluyendo su inicio, bien incidiendo en su tramitación, determinando, por ejemplo, la suspensión del proceso o provocando anticipadamente su terminación.

『. Con todas sus variantes, no han dejado de destacarse las ventajas de la mediación reparadora como medio de resolución de conflictos penales.

Ventajas -se dice- para la víctima pues, amén de expresar sus sentimientos de miedo, rencor o venganza, la mediación le reconoce un protagonismo innegable en la solución del conflicto de fondo, al permitir, de un lado, que sea resarcida del daño sufrido; y 
evitar, de otro, que sea objeto de revictimizaciones parecidas a aquellas que soporta cuando la respuesta al delito se ofrece a través del proceso penal.

Ventajas igualmente para el victimario o infractor pues, al enfrentarle con el problema causado y con la víctima, se fomenta su sentido de la responsabilidad y, por lo mismo, la prevención especial y la reinserción. Otra ventaja indudable que para el infractor ofrece la mediación reparadora es que su éxito se traduce para él en un tratamiento penal más favorable para él, lo que, de otra parte, comporta dar efectividad al conocido «principio de intervención mínima».

Y ventajas también para la sociedad: primero, porque soslaya lo que de deshumanización tiene nuestro actual sistema penal y procesal penal, introduciendo la cultura del diálogo en la resolución de conflictos; y, segundo, porque en la medida en que alienta la responsabilización y reinserción social del delincuente, contribuye a disminuir su peligrosidad, favoreciendo así que, a largo plazo, se estabilice la confianza de los ciudadanos en el respeto del Ordenamiento jurídico (prevención general positiva).

En otro orden de cosas, suele también convenirse que otras de las ventajas características de la mediación penal es que permite agilizar la respuesta frente al fenómeno delictivo, comportando, pues, un importante ahorro de esfuerzos y costes para los llamados operadores jurídicos.

\section{La mediación en el Sistema de Justicia penal español: entre la ley y la práctica}

『. Pese al nombre con que se rubrica este trabajo y da pie a estas páginas, la mediación en el sistema de Justicia penal español no se mueve en la disyuntiva «quimera o realidad». La mediación penal no es una quimera. Se trata, por el contrario, de una realidad cuyos términos -como ya se ha tenido la ocasión de adelantar- se mueven en dos planos distintos: el de la legalidad y el de la práctica vigente.

Ocupa el primero de esos planos la mediación penal juvenil o de menores, a la que hace años da cobertura legal la Ley Orgánica 5/2000, de I2 de enero, Reguladora de la Responsabilidad Penal de los Menores (en adelante LORPM) y cobertura reglamentaria el Real Decreto I774/2004, de 30 de julio.

La conocida como mediación penal de adultos ocupa, por su parte, el segundo de los planos, pues, aun carente de regulación legal, ha conseguido, incrustarse en nuestro sistema, al amparo de ciertas experiencias y programas piloto.

\section{III.I. La mediación juvenil o de menores}

『. «... Un interés particular revisten en el contexto de la Ley los temas de la reparación del daño causado y la conciliación del delincuente con la víctima como situaciones que, en aras del principio de intervención mínima, y con el concurso mediador del equipo técnico, pueden dar lugar a la no incoación o sobreseimiento del expediente, o la finalización del cumplimiento de la medida impuesta, en un claro predominio, una vez más, de los criterios educativos y resocializadores sobre los de una defensa social esencialmente basada en la prevención general y que pudiera resultar contraproducente para el futuro».

Las palabras transcritas -extraídas de la Exposición de Motivos de LORPM- son claramente reveladoras del motivo por el que el legislador español, en sintonía con la mayoría de sus homónimos extranjeros, decidió dar marchamo de legalidad a la mediación 
en el ámbito del enjuiciamiento penal de menores. Tal motivo no era otro que la supremacía que, en el contexto del enjuiciamiento de menores de edad penal, cobra la finalidad educativa y resocializadora $(0, \quad$ si se nos permite el esnobismo, «responsabilizadora») frente a la clásica finalidad retributiva y de prevención general del sistema penal. Aquella supremacía permitía, en efecto, experimentar con ciertas políticas criminales permeables al principio de oportunidad, así como validar legalmente lo que, con anterioridad, había sido puesto en práctica a través de diversas experiencias y programas de mediación ${ }^{15}$.

Lejos, sin embargo, de lo que cabía de esperar, el respaldo legal que la mediación penal recibió en este contexto resultó ser tímido y poco atinado.

『. Fue tímido, porque en contra de lo aventurado por la propia Exposición de Motivos de la Ley, la mediación penal se concibe como un procedimiento al que se anuda el sobreseimiento del expediente ya iniciado o la finalización de la medida impuesta, pero no, en modo alguno, la no incoación del proceso o del expediente de reforma. La mediación en este ámbito se configura, por tanto, como un procedimiento intraprocesal; y, además, de carácter institucionalizado, pues es a los miembros del equipo técnico (o a las entidades públicas encargadas de la ejecución de las medidas impuestas) a quienes se confía la labor de mediar entre menor y víctima, en aras a lograr un acuerdo que permita ora sobreseer el expediente incoado por el Ministerio Fiscal, ora dejar sin efecto la medida impuesta.

Atendidos precisamente estos efectos, las modalidades de mediación penal en este ámbito convienen en catalogarse como mediación «before sentencing» y mediación «after sentencing».

A la primera de esas modalidades -a la mediación «before sentencing»- se refiere el artículo I9 LORPM y el artículo 5 del Real Decreto I774/2004, concreción reglamentaria de aquel primero. Su procedencia se supedita a dos presupuestos: ${ }^{\circ}$ ) Que el hecho imputado al menos constituya delito menos grave o falta y; $2^{a}$ ) que, bien por decisión propia bien a instancia del letrado del menor o incluso del propio equipo técnico, el Ministerio Fiscal entienda procedente derivar el conflicto hacia una solución extrajudicial, a cuyo efecto habrá de atender «a la gravedad y circunstancias del hecho y del menor» y, «de modo particular, a la falta de violencia o intimidación graves en la comisión de los hechos». Dándose estos presupuestos, la derivación del asunto a mediación comporta la suspensión de la tramitación del expediente y, eventualmente, como decimos, la conclusión del proceso mediante sobreseimiento y archivo de las actuaciones. Como a nadie escapa, éste es efecto que se sigue si el menor alcanza un acuerdo con la víctima, que puede consistir en la conciliación -esto es, en el reconocimiento por el menor del daño ocasionado, la petición de disculpas y la aceptación de tales disculpas por parte de la víctima- o en la reparación -esto es, en el compromiso del menor de realizar determinadas prestaciones en favor de la víctima o de la comunidad, seguido de su realización efectiva-. Alcanzado pues uno u otro tipo de acuerdo, e incluso cuando la conciliación o reparación no sean posibles por causas ajenas al menor, el Ministerio Fiscal actuará conforme al principio de oportunidad, desistiendo del expediente incoado y solicitando del Juez el sobreseimiento y archivo de las actuaciones (art. I9.2 y 4).

La segunda modalidad de mediación -la mediación after sentencing- ninguna incidencia tiene sobre la tramitación del proceso. Regulada en el artículo 5I.3 LORPM, su eficacia radica en dejar sin efecto la medida impuesta, lo que sucederá cuando el Juez, a propuesta del Ministerio Fiscal o del letrado del menor y oídos el equipo técnico y la representación de la entidad pública de protección o reforma de menores, juzgue que la

${ }^{15}$ Nótese, en este sentido, que previamente a la entrada en vigor de la LORPM ya se habían puesto en marcha varios programas de mediación en Castilla-La Mancha, Cataluña, Madrid, País Vasco y Valencia. 
conciliación del menor con la víctima y el tiempo de duración de la medida ya cumplida expresan suficientemente el reproche que merecen los hechos cometidos por el menor.

『. Este rápido repaso sobre las modalidades de mediación en nuestro ordenamiento vigente ${ }^{\mathrm{r} 6}$ pone ya sobre la pista de los motivos por los que su regulación ha sido merecedora de críticas.

Algunos de esos motivos tienen que ver las garantías esenciales de nuestro sistema de Justicia penal; en concreto, con la presunción de inocencia. En este sentido, son muchos los que entienden que esta garantía se compadece mal con el hecho de que el sobreseimiento del expediente ex artículo ig LORPM se ligue al cumplimiento de determinadas actividades por el menor, toda vez que tal ligazón no deriva de actividad probatoria alguna, sino todo lo más del reconocimiento -explícito o implícito- de los hechos por parte de aquél.

En relación con esto último también se critica la indeterminación legal acerca de qué eficacia procesal debe anudarse a ese reconocimiento de hechos si es que la mediación posteriormente concluye sin éxito o el menor no cumple con los compromisos adquiridos. En concreto, se plantea si en tal clase de supuestos resulta factible fundar una sentencia condenatoria en el hecho de que el menor estuvo inicialmente dispuesto a mediar con la víctima.

Las anteriores, con todo, no son las únicas objeciones que cabe hacer a la regulación legal de la mediación, toda vez que respecto de ella también abundan las lagunas y las deficiencias.

Así, y en cuanto a las carencias, nada hay en la LORPM ni en su Reglamento de desarrollo que permita intuir por cuánto tiempo puede prolongarse la mediación. Nada se dice tampoco sobre la posibilidad de que el Fiscal y/o el Juez de menores fiscalicen el resultado de la actividad mediadora y/o la proporcionalidad del acuerdo alcanzado. Y también se guarda silencio acerca de la posibilidad de que la mediación after sentencing y los efectos que le son característicos puedan tener por referente un acuerdo reparador y no sólo conciliador.

De otra parte, se da la circunstancia de que el legislador ha impuesto en este ámbito soluciones discutibles e incluso incoherentes.

Buena prueba de lo primero es la ya mencionada posibilidad que el Ministerio Fiscal inste el sobreseimiento y archivo de las actuaciones incluso cuando la conciliación o reparación no sean posibles por causas ajenas al menor; previsión en torno a la cual existen pareceres jurisprudenciales discordantes ${ }^{17}$. Así, mientras algunas Audiencia Provinciales niegan que la acusación particular pueda impedir en tales casos el sobreseimiento del proceso, cuya procedencia obedece en exclusiva a la solicitud del Fiscal, otras consideran que la petición de sobreseimiento por el Ministerio Fiscal no resulta vinculante para el Juez, que puede acordar la continuación del proceso a instancia de la acusación particular ${ }^{18}$.

\footnotetext{
${ }^{16}$ Para un análisis detenido de estas modalidades pueden consultarse, entre otros, los trabajos de CASTILLEJO Manzanares, R., «La mediación en el proceso de menores», Revista de Derecho Penal (Lex Nova), 20II (32), pp. 9 a 28.

${ }^{17}$ Esta contradicción jurisprudencial es destacada por la propia Fiscalía General del Estado en su Memoria de 2010, pp. 35 у 36.

${ }^{18}$ Representativo de aquella primera tesis es el AAP de Barcelona (Sección $3^{\text {a }}$ ), de 26 de abril de 2009. La segunda tesis es acogida, por su parte, en AAP de Tarragona (Sección $2^{a}$ ) de I8 de junio de 2007; y AAP (Sección Ia) de Ciudad Real, de I4 de noviembre de 2008.
} 
Incoherente, por su parte, nos parece el ámbito objetivo al que se circunscribe la mediación penal. Y es que si ésta legalmente se justifica en el principio de intervención mínima, así como en su potencial educativo y resocializador respecto del menor infractor, ¿por qué no permitir entonces que aquélla actúe como óbice a la incoación del expediente? ¿por qué reducirla a la denominada delincuencia «bagatelaria»? ¿por qué, en fin, no admitirla respecto de aquellos hechos cometidos con violencia o intimidación graves ${ }^{\mathrm{I}}{ }^{\text {? }}$ ?

\section{III.2. La mediación de adultos}

『. A diferencia de lo que sucede en el ámbito del enjuiciamiento penal de menores, entre las concesiones que nuestro Derecho vigente hace a la Justicia restaurativa no se halla de momento la mediación. Antes al contrario: la única alusión que nuestro Ordenamiento hace a la mediación de adultos es para proscribir su aplicación, si bien sólo respecto de los hechos constitutivos de violencia de género y, más en general, respecto de cuantas materias entran dentro del ámbito de la competencia objetiva de los Juzgados de Violencia sobre la Mujer $^{20}$.

Frente a esta situación de anomia, son muchas las voces que abogan porque se dé cobertura legal a la mediación penal en el ámbito del enjuiciamiento de mayores de edad penal $^{2 \mathrm{I}}$, e incluso por permitirla, con mayor o menor intensidad, en materia de violencia de género $^{22}$. Quienes enarbolan estas iniciativas lo hacen sobre la base de las numerosas experiencias llevadas a cabo en la última década en diversos órganos jurisdiccionales repartidos por toda la geografía española.

Esas experiencias -impulsadas por determinadas entidades privadas e incluso públicas $^{23}$, así como por el Consejo General del Poder Judicial ${ }^{24}$ - son reveladoras de que la

I9 Incoherentes nos parecen también determinados aspectos de la regulación relacionados con su ámbito subjetivo. Tal es el caso, por ejemplo, de que la Ley asuma como punto de partida la capacidad procesal (y, por ende, de obrar) del menor infractor y, sin embargo, de alcanzarse finalmente un acuerdo con la víctima, se exija la conformidad al respecto de sus representantes legales (art. 5 RD I774/2004).

${ }^{20}$ La alusión mencionada es la contenida en el apartado 5 del artículo 87 ter LOPJ, al albur de la redacción dada a este precepto por el artículo 44 de la Ley Orgánica de Medidas de Protección Integral contra la Violencia de Género.

${ }^{21}$ Como botón de muestra de estas voces, baste señalar las iniciativas realizadas por el Foro de la Justicia (Propuestas de la Comisión III. Aprobadas por el Pleno de io de febrero de 2005); el Grupo de Estudios de Política Criminal (en Una propuesta alternativa al sistema de penas y su ejecución y a las medidas cautelares personales, Valencia, 2005, pp. 44y 45); y la Sociedad Española de Victimología (Conclusiones del Seminario sobre «La introducción de los intereses de la víctima en el sistema penal ante las reformas legales en curso en España), Valencia 5 y 6 de mayo de 2005. También GEMME (Grupo de Magistrados Europeos por la Mediación) ha ofrecido su ayuda al Ministerio de Justicia, con vistas a potenciar la mediación en nuestro ordenamiento.

Las iniciativas han partido igualmente de algunos Grupos Parlamentarios, que vieron en la tramitación de la reciente reforma del Código Penal un momento idóneo para dotar de cobertura legal a la mediación. Estas iniciativas no fueron, sin embargo, acogidas por el Parlamento con base en que será la tan esperada reforma de la Ley de Enjuiciamiento Criminal el momento adecuado para introducir oficialmente la mediación penal de adultos en nuestro Ordenamiento.

${ }^{22}$ En este sentido, se pronuncian, entre otros, Ríos MARTín, J.C., La mediación penal y penitenciaria. Experiencias de diálogo en el sistema penal para la reducción de la violencia y el sufrimiento humano, ed. Colex, Madrid, 2008, p.IO7; Alhambra PÉREZ, P., «El Juez ante la mediación penal», en La mediación. Presente, pasado y futuro de una institución jurídica, op. cit., pp. II2 y IIz. También, en la misma obra, MARTíneZ DE AGUIRRE AldAZ, M. «Espacios para la mediación en nuestro ámbito penal. Una reflexión a partir de la experiencia belga y francesa», p. 86.

${ }^{23}$ Destacan, por ser las más antiguas y pioneras, las experiencias puestas en marcha por el Departamento de Justicia de la Generalitat de Cataluña. A su impulso también respondió la creación en el año 2000 del primer Servicio de Mediación y Reparación Penal de Adultos; servicio que hoy comparte sede con los Juzgados de Instrucción y de lo Penal de Barcelona y que cuenta con delegaciones en todas las capitales catalanas de provincia. 
mediación penal de adultos se ha incrustrado de facto en nuestro sistema ${ }^{25}$, generalmente por la vía de vincular su éxito -i.e.: el alcance de un acuerdo entre víctima e infractor- a la obtención de ciertos beneficios que nuestra legislación penal sustantiva anuda a la reparación de la víctima y, en menor medida, a la conciliación del infractor con ésta. Así, en la mayoría de los casos la reparación de los daños ocasionados por el infractor se ha hecho valer como una atenuante genérica ex artículo $2 \mathrm{I} .5^{\mathrm{a}} \mathrm{CP}$, como una atenuante muy cualificada ex artículo $2 \mathrm{I}$. $7^{\mathrm{a}} \mathrm{CP}^{26}$ o incluso como atenuante específica de determinados tipos delictivos como los relativos a la ordenación del territorio y el urbanismo, la protección del patrimonio histórico y el medio ambiente (art. $340 \mathrm{CP}$ ). Tampoco han faltado los casos en que la reparación se ha ligado a la suspensión de la ejecución de la pena ya impuesta (arts. 8 I. $3^{\mathrm{a}}$ y $87 \mathrm{CP}$ ) o a la sustitución de esta última (art. $88 \mathrm{CP}$ ).

Amén de lo anterior, las experiencias revelan que han sido también muchas las ocasiones en que se ha buscado cobijo en instituciones procesales para dotar al acuerdo mediador de eficacia mitigadora o alternativa a la pena. En este sentido, hay Juzgados, por ejemplo, que se han avenido a acordar el sobreseimiento (provisional, pero también libre) de las actuaciones; a transformar el procedimiento por delitos en juicio de faltas; o a anudar a aquel acuerdo la eficacia procesal propia del reconocimiento de hechos (art. 779.I. ${ }^{a}$ LECrim). La institución de la conformidad también ha jugado un papel importante en este contexto, habida cuenta que la obtención de un acuerdo en mediación se ha servido de la conformidad para lograr las ventajas -consensuadas con la acusación o previstas ex legepropias de ésta (arts. 655 y ss, 784.3, 787 y 8 o I LECrim).

Con todo, han sido muchas otros las experiencias y proyectos pilotos desarrollados en los últimos años con el apoyo de Administraciones autonómicas y locales como las del País Vasco, Valencia, La Rioja, Valladolid o Burgos y de determinadas asociaciones como Amepax o la asociación Apoyo en Madrid.

${ }^{24}$ El impulso a la mediación penal por parte del Consejo General del Poder Judicial se recoge explícitamente en el Plan de Modernización de la Justicia, aprobado por su Pleno el i2 de noviembre de 2008. Este reconocimiento no es sino exteriorización de lo que el órgano de gobierno de Jueces y Magistrados ya venía haciendo años atrás. No en vano, fue el Consejo el que alentó y coordinó el desarrollo de experiencias piloto sobre mediación penal en las que participaron más de cuarenta Juzgados de Instrucción y de lo Penal de toda España, y cuyos resultados se recogen en el estudio «Justicia Restaurativa y Mediación penal: Análisis de una Experiencia (2005-2008)».

${ }^{25}$ Son muchas ya las alusiones de nuestra jurisprudencia a la mediación penal. Sirva por todo ejemplo ésta reciente extraída de la Sentencia de la Audiencia Provincial de Guipúzcoa (Sección Ia ), de I6 de marzo de 2010: «La mediación penal es uno de los instrumentos de plasmación del modelo de justicia restaurativa. Este modelo trata de lograr la pacificación social e individual involucrando al victimario y a la víctima en la consecución de una respuesta consensuada a la infracción penal bajo el control del Estado. De esta manera se logra la pacificación social (el Estado garantiza que la respuesta convenida, además de ser una expresión de una voluntad libre, permita una ratificación de la vigencia del orden penal como instrumento hábil para la protección de los bienes jurídicos fundamentales) y la pacificación individual (la víctima obtiene la reparación del daño y el victimario una reacción dúctil a su integración social positiva).

${ }^{26}$ En alguna ocasión, nuestro Alto Tribunal -Sentencia del Tribunal Supremo de 20 de octubre de 2006ha negado la posibilidad de anudar, siquiera por analogía, los beneficios propios de la atenuante de reparación a los supuestos en que la mediación aboca únicamente a una reconciliación entre infractor y víctima. En apoyo de esto último se razona que «la mera participación del recurrente en un programa voluntario de mediación penal, aun con resultado positivo, no implica efectiva reparación. El perjudicado desde un principio renunció a toda clase de indemnizaciones, así que tanto da que no exista daño a reparar o el existente sea renunciado, ya que en ninguno de ambos casos se ofrece la posibilidad de reparar y realmente, en este caso, no se ha reparado nada (...) En definitiva, sin reparación real y efectiva, total o parcial, no puede haber atenuación». Que la conciliación entre infractor y víctima no se considere reparación en este sentido o en el más amplio sentido del artículo II2 CP no debe tomarse, sin embargo, en el sentido de entender que a la conciliación resultante de un procedimiento mediador se le niegue eficacia en la dosimetría penal. Antes al contrario: como revela la propia Sentencia citada ut supra, el beneficio penológico se produce, si bien por vía de individualización de la pena. 


\section{Ante el reto de dar cobertura legal a la mediación en el enjuiciamiento penal de adultos}

『. Dar cobertura legal a la mediación penal en nuestro sistema no es labor que apriorísticamente se dibuje exenta de dificultades. Al contrario: serán muchas las trabas -y de enjundia- las que habrán de sortearse, si es que el legislador español se decide final y abiertamente a ello.

Los obstáculos a que nos referimos son, obviamente, de índole jurídico, pero también presupuestario e incluso sociológico. Institucionalizar la mediación penal en nuestro sistema demandará, en efecto, disponer de los medios, personales y materiales necesarios para hacer frente a la infraestructura administrativa que exige un servicio institucionalizado de mediación. Y también exigirá informar y concienciar a la ciudadanía y a los profesionales jurídicos de las pretendidas bondades que pueden seguirse de la implantación de un modelo tan ajeno a nuestra tradición jurídico-penal como el aquí analizado.

Con no ser baladíes, las dificultades recién mencionadas resultan en nuestra opinión insignificantes comparadas con los problemas legales y constitucionales a los que habrá que enfrentarse el legislador para insertar la mediación en nuestro actual sistema de Justicia penal.

Un primer escollo -sin duda, también en orden de importancia- será encajar el instituto en un sistema como el nuestro basado en principios no ya distintos sino radicalmente contrarios a aquellos en que descansa el modelo de Justicia restaurativa.

A lo anterior deben sumarse los riesgos que habrán de asumirse respecto de las garantías esenciales al proceso penal y a la mediación misma.

Finalmente, no debe perderse de vista que el éxito de la mediación penal entre nosotros dependerá en buena medida de cómo se perfile técnicamente su regulación; extremo respecto del que -entendemos- mal haría en tomarse como ejemplo la actual regulación de la mediación penal juvenil o de menores, atendidos sus defectos y lagunas.

Detengámonos, siquiera brevemente, en estos aspectos.

\section{IV.I. La mediación en clave de principios}

『. Como es sabido, el sistema de Justicia penal español se halla secularmente informado por el principio de legalidad y de oficialidad. Que esto sea así responde al entendimiento de que, por encima de cualquier interés particular, existe un interés público en la represión de determinadas conductas que, precisamente por resultar reprobables al conjunto de la sociedad, se tipifican como ilícitas y resultan merecedoras de sanción (principio de legalidad penal). Es, por tanto, el interés público en no dejar sin respuesta determinadas conductas tipificadas como delitos, públicos o semipúblicos, o como faltas lo que justifica que el Estado asuma en exclusiva el ius puniendi y lo que impide a un tiempo predicar de los particulares cualquier derecho subjetivo a perseguir y castigar o a que se persigan y/o castiguen aquellas infracciones penales.

Coherentemente con la consideración del Derecho Penal como asunto de interés público, la aplicación de la mayor parte de esta parcela del Ordenamiento jurídico se reserva, también en exclusiva, al proceso. Sólo, por tanto, los Jueces y Magistrados integrantes de aquel orden de la jurisdicción (principio de exclusividad jurisdiccional) y sólo a 
través del proceso cabe satisfacer el interés público que subyace a la mayoría de normas penales (principio de legalidad o necesidad procesal penal).

La configuración del proceso penal como instrumento necesario para actuar el Derecho Penal explica, a su vez, que la voluntad de los sujetos afectados por el hecho delictivo no resulte determinante respecto de su inicio y su tramitación, toda vez que, para los denominados órganos oficiales de la persecución penal, se impone la obligación de incoar o de instar la incoación del proceso penal ante la noticia de un hecho aparentemente delictivo y de no prescindir del proceso mientras exista materia criminis (principio de necesidad $y$ de oficialidad). Paladina manifestación de esta obligación es la función que constitucional, legal y estatutariamente incumbe al Ministerio Fiscal de defender la legalidad, los derechos de los ciudadanos y el interés público tutelado por Ley, ejercitando las acciones penales que considere procedentes allí donde los hechos revistan carácter de delito público o semipúblico (principio de legalidad o de obligatoriedad de la acción penal).

Siendo los expuestos los principios básicos que dibujan la esencia de nuestro actual sistema penal y procesal penal, a nadie escapa que Ley y Constitución obstan, hoy día, a que los sujetos implicados en un conflicto penal de dimensión pública o semipública puedan por su sola voluntad sustraer tal conflicto de la decisión de los órganos jurisdiccionales o influir decisivamente en el instrumento -el proceso- necesario para resolverlo ${ }^{27}$. A menos, por tanto, que se destipifiquen determinadas conductas delictivas reservando la solución del conflicto subyacente a estas últimas a la mediación (que ya no sería penal) o que se excluya de ésta cualquier eficacia penal procesal, la incorporación de la mediación en nuestro sistema de Justicia penal exigirá que se emprenda una profunda reforma de este último; reforma que -apostillamos- no debería ser sólo legal sino también constitucional.

Así, en tanto la mediación penal supone residenciar en el infractor y víctima la respuesta que merece el hecho delictivo y, por ende, sustraer de los órganos jurisdiccionales integrantes del orden penal la función que constitucionalmente se les tiene exclusivamente asignada, quizá resultase necesario modificar el texto constitucional, a fin de matizar que el principio de exclusividad jurisdiccional que en él se recoge (artículo II7.3 CE) encuentra un punto de inflexión en el instituto de la mediación penal ${ }^{28}$.

En la misma línea, tanto se opte por configurar la mediación como un procedimiento preprocesal como intraprocesal de resolución de conflictos en línea de lo permitido por la DM 200I/220/JAI ${ }^{29}$, entendemos que aquella reforma ha de pasar necesariamente por acoger el principio de oportunidad en nuestro sistema de Justicia penal.

\footnotetext{
${ }^{27}$ Nótese, en este sentido, que un sector de nuestra doctrina entiende que las experiencias piloto llevadas a cabo en nuestro país respecto de la mediación penal de adultos son no ya alegales sino ilegales justamente, por contrariar los principios de necesidad y de oficialidad en que descansa nuestro sistema procesal penal. Así opinan, entre otros, MANZANARes SAMANiego, J. L., «La mediación penal», en Diario La Ley, núm. 69oo, de io de marzo de 2008; y MARTín Diz, F., La mediación: sistema complementario de Administración de Justicia, op. cit., 365 y 366.

No todos mantienen, en cambio, este sentir, pues hay quien opina que el artículo 2I CP e incluso la propia DM 200I/220/JAI dotan a la mediación penal de la habilitación legal mínima para recurrir a ella. Tal es el parecer, por ejemplo, de CARRIZO GonZÁLEZ-CASTELL, A., «La mediación penal en España», en La mediación en materia de familia y Derecho penal: estudios y análisis (Coord. MARTín DiZ, F.), ed. Andavira, Santiago de Compostela, 20II, pp. 234 y 235.

${ }^{28}$ Utilizamos el adverbio «quizá», porque consideramos que la reforma constitucional en este punto podría soslayarse por la vía -que propugnamos y expondremos más adelante- de someter a control judicial los acuerdos alcanzados vía mediación, así como la adecuación de ésta y aquéllos a las garantías y derechos consagrados en nuestro Ordenamiento.

${ }^{29}$ Vid. nota 8.
} 
En su versión «reglada», el principio de oportunidad comporta la facultad, si es que se dan las condiciones legalmente establecidas al efecto, de que los denominados órganos oficiales de la persecución penal -significadamente, el Ministerio Fiscaldispongan del ejercicio de la acción penal con vistas a evitar el proceso o ponerle fin anticipadamente. Esto sentado, es claro, como decimos, que sólo este principio permitirá fundar las bases de una mediación penal preprocesal (y, eventualmente, excluyente del proceso) o de una mediación intraprocesal (y, eventualmente, cercenadora de la completa tramitación del proceso). Y también nos parece claro que la instauración de este principio en el sistema exigiría -sin el «quizá»- una modificación constitucional, que en este punto habría de alcanzar al principio de legalidad en su doble modalidad de principio rector del Derecho Penal (art. 25 CE) y de la actuación del Ministerio Público ${ }^{30}$ (art. I24 CE).

『. Relacionado con lo anterior, se impone hacer notar que la implantación de la mediación también comportará profundos costes en materia de igualdad, proporcionalidad y seguridad jurídica.

El empleo de la oportunidad, aun en su modalidad reglada, comporta implícita, en efecto, la posibilidad de otorgar un tratamiento y soluciones distintas ante hechos idénticos y, por lo mismo, una gran inseguridad en torno a la respuesta jurídica que pueden merecer las conductas delictivas y a su exigible proporcionalidad. Pues bien, como manifestación del principio de oportunidad reglada, la mediación penal comportará estos mismos riesgos, si bien agravados por la circunstancia de que del acuerdo mediador pueden resultar soluciones distintas para casos similares, habida cuenta que son las partes las que dotan de contenido al acuerdo.

IV.2. La mediación en clave de derechos y de garantías procesales

『. Una de las críticas más frecuentemente ligadas a la implantación de la mediación penal en nuestro sistema penal atañe a la presunción de inocencia. Como vimos con ocasión de analizar la mediación juvenil o de menores, la crítica aparece usualmente unida a dos factores.

De un lado, a la posibilidad de que la sola decisión del infractor de someterse a mediación pueda, de fracasar ésta y no cristalizar en un acuerdo, llegar a tener trascendencia probatoria y ser valorada para fundar una sentencia de condena.

De otro, a la posibilidad de que el acuerdo resultante de la mediación comporte la asunción de determinados compromisos por parte del infractor y/o la imposición de una pena (más favorable en comparación con la que resultaría de no haberse alcanzado un acuerdo con la víctima), sin que se haya desarrollado actividad probatoria alguna que permita fundar un juicio de culpabilidad. Así sucedería, por ejemplo, si el acuerdo alcanzado quedará finalmente reflejado en un escrito de conformidad con el escrito de acusación o en un escrito de conformidad presentado conjuntamente por acusación y defensa.

Hablando en primera persona, debemos comenzar por señalar que, en nuestra opinión, predicar abstracta y genéricamente de la mediación penal su incompatibilidad con el derecho a la presunción de inocencia constituye un dislate. Sólo -nos parece- a la luz de

${ }^{30}$ En vista de que este principio de oportunidad reglada cuenta ya con manifestaciones en nuestro sistema procesal penal, algunas tan relevantes como el instituto de la conformidad, cabría sostener que tampoco en este punto sería necesaria una reforma constitucional. Sea como fuere, lo que resulta indiscutible es que esa reforma sería cuando menos conveniente para dotar de coherencia interna al sistema. 
la que sea su regulación legal cabrá sostener tal clase de afirmaciones. Lo demás es elucubrar sobre hipótesis.

Fundar, de otra parte, en la presunción de inocencia la imposibilidad de que la apertura y cierre de la mediación -frustrada- puedan ser tenidos en consideración por el Juez o Tribunal sentenciador a la hora de formar su convicción sobre la certeza de los hechos objeto de enjuiciamiento también, a nuestro juicio, resulta desacertado. En este contexto, compartimos la opinión de quienes entienden que, aun carente del valor de prueba, el solo dato de acceder al procedimiento de mediación es circunstancia que no es neutra desde la perspectiva global de la valoración de la prueba (más, si ha precedido un reconocimiento total o parcial de los hechos por parte del infractor), como no lo es tampoco el reconocimiento de hechos por parte del imputado que, de facto, suele preceder a la mediación $^{3 \mathrm{I}}$. La voluntad de someterse a la mediación puede, pues, tener trascendencia probatoria, lo que es muy distinto de afirmar que aquella voluntad baste por sí sola para fundar un juicio de culpabilidad, pues sólo en este último caso cabría entender violada la constitucional presunción de inocencia.

En cuanto a la posibilidad -en absoluto remota- de que el proceso penal concluya con una sentencia condenatoria tras una mediación penal y sin que preceda actividad probatoria alguna, no podemos por menos que reconocer que tal consecuencia difícilmente se concilia con la presunción de inocencia. Con todo, la incoherencia -lógica y constitucional- de admitir una sentencia condenatoria sin prueba de cargo lícita y suficiente no es defecto que quepa atribuir directa y exclusivamente a la mediación penal, si no más bien a otro tipo de negocios-jurídicos con el que aquella se relaciona. Nos referimos, obviamente, a la conformidad ${ }^{32}$.

『. Otra de las amenazas que se cierne sobre la mediación penal afecta a un tiempo a determinadas garantías y derechos fundamentales de alcance procesal, como el derecho a no declarar contra sí mismo y a no confesarse culpable (art. 24.2 CE), y a una de las notas esenciales de la mediación: la voluntariedad.

La filosofía que inspira la mediación penal implica -ya lo hemos dicho- que el sometimiento de infractor y víctima al procedimiento mediador debe ser fruto de su libre voluntad; de su sólo y exclusivo deseo de participar en la solución del conflicto que subyace a la conducta delictiva. Resultaría, por tanto, inadmisible que la víctima se viera impelida a participar en la mediación a fin de evitar, por ejemplo, reproches de intransigencia o de falta de magnanimidad, o que se compeliera al infractor a hacer otro tanto a fin de soslayar determinadas consecuencias negativas que pudiera seguirse de no someterse a la mediación. Con ser esto incuestionable, lo cierto, sin embargo, es que existe el riesgo de que la voluntad del infractor de someterse a la mediación resulte mediatizada no ya tanto por obtener los beneficios penológicos que se liguen a la reparación o conciliación con la víctima, cuanto por evitar la agravación punitiva que pudiera producirse de rechazar el infractor someterse a ella.

El peligro al que nos referimos es real. Se ha actualizado ya en el sistema actual de las conformidades y, más concretamente, en aquellas modalidades de conformidad negociada que, aunque no expresamente reguladas en la Ley de Enjuiciamiento Criminal, proliferan en la práctica de nuestros Juzgados y Tribunales. La práctica revela, en efecto, que tras el incremento exponencial de las conformidades en nuestro sistema no sólo existe el deseo del imputado de obtener una rebaja o suspensión de la pena, sino de eludir un agravamiento de su situación si es que opta por la normal tramitación del proceso y no por

${ }^{31}$ Del Moral García, A. «La mediación en el proceso penal. Fundamentos, problemas, experiencias», cit., pp. 64 a 66.

${ }^{32}$ De La Oliva Santos, A., «Presunción de inocencia, prueba de cargo y sentencia de conformidad», en Revista (on line) Derecho y Proceso, núm. II (2005-2006), http://www.ucm.es/info/procesal/revista.htm. 
la más célere en que se traduce la conformidad. Esta última consecuencia -la agravación de la situación del acusado si es que rechaza un pacto de conformidad- responde a cierta praxis que bien puede expresarse mediante el siguiente silogismo: «Si debe premiarse al que se conforma por lo que de ahorro supone su conformidad a la Administración de Justicia, debe castigarse al que no se conforma por lo que de no colaboracionista tiene su actitud». Lo diremos de otra forma: en la práctica, quien apuesta por ejercer activamente su derecho de defensa en el juicio oral, parte de una situación concebida para propiciar la conformidad: el Ministerio Fiscal sobrecarga dentro de los límites que le permite el artículo $66 \mathrm{CP}$ la pena solicitada en previsión de ofrecer una rebaja de esta pena si existe conformidad; luego, si ésta no se produce no ya es sólo que el imputado no pueda acceder a esa rebaja, es que se enfrenta como punto de partida a una solicitud «al alza» de la pena y a un resultado en que el Juzgado o Tribunal enjuiciador puede justificar ese incremento penológico o la no obtención de determinados beneficios como la suspensión de la condena en su rechazo a la conformidad.

A nuestra anterior afirmación de que la actual configuración legal de la conformidad resulta incoherente desde la perspectiva de la presunción de inocencia, debe, pues, añadirse ahora que su práctica -el modo que se negocian las conformidades o en que se acogen las penas «infladas» del Ministerio Fiscal en sentencia- trasluce una voluntad más ficticia que real de someterse a ellas y -lo que nos parece mucho más grave- un peligro real y concreto de que nuestros operadores jurídicos superpongan razones meramente utilitaristas al derecho a la defensa, el derecho a no declararse culpable y a otros derechos y garantías de que disfruta el imputado y que son inherentes al proceso penal ${ }^{33}$.

Idéntico peligro planea sobre la mediación penal, máxime si su regulación anuda al logro de un acuerdo entre infractor y víctima un desenlace procesal anticipado, se consolida la idea de potenciar la mediación derivando hacia ella un considerable número de asuntos y se restringe su ámbito objetivo a la denominada «delincuencia bagatelaria». Se impone, pues, que el legislador ponga desde un principio los medios para evitarlo. De otro modo, la mediación perderá su razón de ser, su antropología, para convertirse en un disfraz de corte muy similar a las actuales conformidades.

\section{IV.3. Algunas propuestas con vistas a la implantación legal de la mediación en nuestro sistema}

『. Expuestos los principales escollos que obstan al objetivo de dar acomodo legal a la mediación penal en nuestro Ordenamiento, terminamos con algunas propuestas que, a nuestro modo de ver, permitirán sortear aquellos escollos, sin sacrificio -importa subrayarlo- de la filosofía y objetivos que animan el instituto.

\footnotetext{
${ }_{33}$ La realidad del peligro se infiere claramente de las SSTC 75/2007, de I6 de abril, y 76/2007, de i6 de idéntica fecha. A la primera de las citadas, corresponden estas palabras que, por compartirlas casi en su totalidad, transcribimos: «... En el presente caso, la Sentencia de primera instancia justifica la no imposición de la pena en el grado mínimo, por un lado, en 'que esto es lo que se ofreció a los acusados para el caso de que se conformaran con los hechos objeto de la acusación y rechazaron aceptar', de modo que, no concurriendo circunstancias modificativas, no se encuentran motivos para rebajar la pena solicitada por el Ministerio Fiscal y, por otro lado, en la propia actitud de los acusados durante el juicio, pues si hubieran reconocido los hechos, o al menos no hubieran negado lo más evidente, y no hubieran obligado a hacer un juicio larguísimo se justificaría el 'que se les tratara con más magnanimidad'. En dichas circunstancias, como ponen de manifiesto el recurrente y el Ministerio Fiscal, cabe apreciar un déficit de la motivación constitucionalmente exigible, pues ni de la anterior argumentación ni de la relación de hechos probados se infiere la ponderación de los criterios legales de individualización de la pena. Y es de señalar, muy destacadamente, que la justificación de la pena impuesta en el hecho de que el acusado, en ejercicio de sus derechos fundamentales a no declarar contra sí mismo y a no confesarse culpable (art. 24.2 CE), no se conformara con la pena solicitada por la acusación y negara los hechos más evidentes según la apreciación judicial, resulta a todas luces manifiestamente irrazonable $y$ constitucionalmente inadmisible, por lesiva de los citados derechos fundamentales» (la cursiva es nuestra).
} 
No hemos de insistir lo suficiente en que las propuestas que realizamos se limitan a las cuestiones que entendemos determinantes en uno y otro sentido. Se trata, en concreto, del ámbito objetivo y subjetivo al que puede alcanzar la mediación y de su control jurisdiccional.

Antes, con todo, de exponer las claves que, desde nuestro particular punto de vista, contribuirán positivamente al éxito de la mediación penal, es preciso dejar claro que la Ley que venga a regularla habrá de ser una ley de carácter estatal y destinarse específicamente a ella. La claridad de lo primero -el carácter estatal de la hipotética Ley reguladora de la mediación penal-, viene dibujada por el artículo I49.I.6 ${ }^{a}$ CE que, como es sabido, reserva exclusivamente al Estado la regulación de cuantas materias afecten al Derecho Penal y Procesal. Lo segundo -la especificidad de la Ley y su autonomía por ende del Código Penal y de la Ley de Enjuiciamiento Criminal-, viene impuesto, por su parte, por los principios y caracteres de la mediación; principios que, como hemos visto, difieren en mucho de los que son propios a nuestro actual regulación penal y procesal penal. Esto último, en nada impediría -todo lo contrario- que la mediación tuviera su pertinente reflejo en el Código Penal y en la Ley de Enjuiciamiento Criminal, sobre todo si el legislador se decanta por un modelo de mediación penal intraprocesal y con posible repercusión penológica.

『. La primera de pieza clave para la viabilidad y eficacia de la mediación penal en nuestro sistema radica, según ya hemos adelantado, en la correcta delimitación de su ámbito objetivo y subjetivo.

Por lo que hace a la delimitación material de las conductas susceptibles de ser sometidas a esta técnica de resolución de conflictos, un nutrido sector doctrinal apuesta por restringir el ámbito objetivo de la mediación a las conductas constitutivas de faltas y de delitos privados o semipúblicos, así como a determinados delitos públicos: aquéllos castigados con pena menos grave -no superior, por tanto, a cinco años de prisión-. Tras esta opción militan, entre otros, dos argumentos de peso: (I) las concesiones al principio de oportunidad quedarían reducidas a las conductas menos reprobables para el conjunto de la sociedad, equiparándose en este sentido a lo previsto en el ámbito del enjuiciamiento penal de menores, y; (2) tal y como confirman las experiencias mediadoras realizadas en este ámbito, al tratarse de infracciones penales leves, la mediación podría resultar más atractiva para infractor y víctima, por lo que se potenciaría su uso.

Sin desmerecer los anteriores argumentos, personalmente somos partidarios de dotar a la mediación de un ámbito objetivo considerablemente más amplio.

Que las conductas «bagatelarias» o «de bagatela» constituyan un campo abonado para la mediación no necesariamente conduce a excluir el resto de las conductas delictivas de aquel ámbito. Al contrario: si se confía en la mediación como instrumento para la pacificación social, si se predica la conveniencia de instaurar la cultura del diálogo para solventar los conflictos, si debe, en fin, procurarse la concienciación del infractor en reparar a la víctima del perjuicio causado con su conducta, renunciar a tales objetivos tratándose de delitos graves resulta un claro contrasentido. A nuestro juicio, por tanto, la propia filosofía que inspira la mediación aconseja que ningún hecho delictivo deba, por razón de su gravedad, quedar apriorísticamente excluido de la mediación. Cuestión distinta es que otros criterios como la naturaleza del delito o la relación entre infractor y víctima puedan servir posteriormente como parámetros de selección de los concretos casos «mediables».

En la misma línea, pero en otro orden de cosas, no creemos que la ampliación del ámbito objetivo de la mediación penal deba entenderse inexorablemente ligada a una concesión absoluta al principio de oportunidad en detrimento del principio de la legalidad. La determinación del ámbito objetivo de la mediación penal no tiene por qué condicionar la eficacia del acuerdo que se obtenga a resultas de ella. Así, tratándose de delitos privados o delincuencia «de bagatela» podría admitirse el sobreseimiento o beneficiar al infractor con 
la eficacia característica de la conformidad, mientras que tratándose de delitos graves al acuerdo podría seguir únicamente una eficacia mitigadora o alternativa de la pena.

Predicar, como lo hacemos, un amplio objetivo para la mediación no debe interpretarse, con todo, en el sentido de entender que nuestro parecer es favorable una mediación objetivamente universal. No es así. En este sentido, compartimos la opinión de que las faltas o delitos sin víctima (los conocidos como delitos de peligro) o en que la víctima es un ente público o un colectivo indeterminado de personas deberían quedar extramuros de la mediación, pues, bien mirado, utilizar ésta allí donde no hay una víctima concreta no deja de ser un artificio ${ }^{34}$. Con esto -nótese bien- no queremos decir que la reparación no pueda tener eficacia jurídica en esta clase de ilícitos penales, pero sí subrayar que, a tal efecto, no son necesarios terceros mediadores. Se trata, por decirlo llanamente, «de un viaje para el que no son menester alforjas».

Cuanto se acaba de decir conecta -y con esto nos adentramos ya en el ámbito subjetivo-con la posibilidad de permitir la mediación en aquellos casos en que sean varios los infractores y/o varias las víctimas; posibilidad por la que apostamos. No se vea en esto contradicción alguna respecto de lo anteriormente dicho para las infracciones sin víctima o en las que la víctima se equipara con una colectividad o con el propio interés del Estado: negar la mediación para estas infracciones responde a nuestra personal convicción de que, tras ellas, huelga realmente la posición contradictoria entre dos partes respecto de las que se haya de mediar; tratándose, en cambio, de infracciones con pluralidad de víctimas y/o de infractores sí existen dos posiciones enfrentadas sólo que integradas por una pluralidad de sujetos. Más allá, pues, del coste anímico que para la víctima puede suponer enfrentarse con varios agresores o de la dificultad que para el infractor puede comportar reparar a sus víctimas cuando están sean varias, no vemos obstáculo alguno en extender la mediación a estos supuestos ni motivo para impedir que la decisión de un mismo hecho delictivo pueda solventarse para alguno de los sujetos implicados en él mediante mediación y no para el resto. Antes bien: se trata de una solución ésta acorde con el carácter personalísimo que se predica de la mediación y fácil de materializar, además, mediante la creación de piezas separadas.

El mismo carácter personalísimo a que nos acabamos de referir impediría, también en nuestra opinión, extender la mediación a aquellos casos en que infractor y/o víctima no estuvieran en pleno uso de sus facultades mentales, ya que en estos supuestos faltaría la voluntad de someterse libre y voluntariamente a ella. Y lo mismo cabría sostener respecto de los supuestos en que la víctima fuera un menor de edad, si bien -no se nos escapa- esto contrasta con lo previsto en la regulación de la mediación penal de menores, en la que expresamente se sanciona esta posibilidad.

『. A lo largo de las páginas precedentes hemos dejado entrever nuestra inclinación a favor de un modelo intraprocesal de mediación caracterizado por la oficialidad, esto es, por residenciar en los órganos oficiales de la persecución penal la decisión de derivar a mediación aquellos casos que, teniendo encaje primario en el ámbito legalmente previsto, se presten mejor a ello de acuerdo con unos parámetros o criterios previamente establecidos. Ciertamente este modelo por el que apostamos presenta como inconveniente demorar la tramitación del proceso penal, que habrá de dejarse en suspenso hasta que finalice la mediación e incluso hasta el cumplimiento de los compromisos pactados. Frente a este inconveniente -por lo demás, predicable de la mediación preprocesal sólo que en relación al comienzo del proceso y susceptible de ser reducido mediante la fijación de plazos máximos-, la derivación a la mediación en el seno de un proceso en curso presenta, en nuestra opinión. la enorme ventaja de permitir el control jurisdiccional de sus

34 Entre otros, Manzanares Samaniego, J. L., Mediación, conciliación y reparación en el Derecho Penal (Dir. C. Romeo Casabona), Ed. Comares, Granada, 2007, pp. 55 y 56 y; Martín Diz, F. La mediación: sistema complementario de Administración de Justicia, op. cit., p. 354. 
presupuestos, caracteres y efectos y, de sortear, si se introducen los convenientes resortes legales, los riesgos que, en materia de derechos y garantías procesales, hemos visto se proyectan sobre la mediación. 